\title{
Special features of evaporation of water-salt solutions on a horizontal heating surface
}

\author{
Nina Mironova ${ }^{1, *}$, Vladimir Morozov $^{2}$, and Sergey Elistratov ${ }^{1}$ \\ ${ }^{1}$ Novosibirsk State Technical University, 630073 Novosibirsk, Russia \\ ${ }^{2}$ Kutateladze Institute of Thermophysics SB RAS, 630090 Novosibirsk, Russia
}

\begin{abstract}
Experimental investigate the process of evaporation of watersalt solutions on the horizontal heating surface at a temperature of $90^{\circ} \mathrm{C}$. It was revealed that there are differences in the process of evaporation of hydrous solutions of salts forming and not forming water-salt hydrates. The absence of hydrates of salts in hydrous solutions $\mathrm{NaCl}, \mathrm{CaCl}_{2}$ and $\mathrm{CsCl}$ made it possible to fix the rate of formation of a solid phase (nucleation) in the volume of the supersaturated solution.
\end{abstract}

\section{Problem Statement}

The efficiency of absorption thermotransformers (ATT) depends directly on the ability of the working fluid to absorb steam. As working fluid for ATT, water-salt solutions are most widely used. The higher their absorption capacity, the better the performance of absorption chillers and heat pumps.

Water-salt solutions have the greatest capacity for absorption near the equilibrium crystallization line. In Fig. 1 shows the solubility curves of various salts as a function of temperature. In practice, it is customary to produce work processes in ATT with less concentrated solutions to eliminate the phenomenon of solution crystallization, especially in regenerative heat exchangers. In general, this reduces the efficiency of the desorption and absorption processes, increases the total specific quantity of metal of the design.

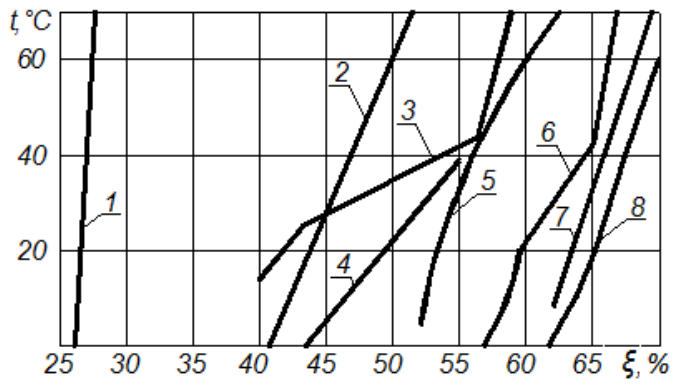

Fig. 1. Dependence of the mass fraction of salts solubility in water on temperature [1]: $1-\mathrm{NaCl} ; 2-$ $\mathrm{LiCl} ; 3-\mathrm{CaCl}_{2} ; 4-\mathrm{LiCl}_{-\mathrm{CaCl}} ; 5-\mathrm{LiCl}-\mathrm{LiNO}_{3} ; 6-\mathrm{LiBr} ; 7-\mathrm{LiCl}-\mathrm{CsCl} ; 8-\mathrm{CsCl}$.

\footnotetext{
* Corresponding author: mironovaNina@inbox.ru
} 
However, for batch machines (fig. 2) with combined "absorber-desorber" and "condenser-evaporator" devices, the formation of salt crystals in solution as a solid dispersed phase (volumetric nucleation process), can on the contrary result in improved effectiveness.

It can be seen (fig. 1) that there except lithium bromide are a number of salts and their mixtures that have a degree of solubility in water higher than lithium bromide. In addition, in an aqueous solution, widely used in practice, the salt $\mathrm{LiBr}$ exists as hydrates $\mathrm{LiBr} \cdot \mathrm{H}_{2} \mathrm{O}$, $\mathrm{LiBr} \cdot 2 \mathrm{H}_{2} \mathrm{O}, \mathrm{LiBr} \cdot 3 \mathrm{H}_{2} \mathrm{O}, \mathrm{LiBr} \cdot 5 \mathrm{H}_{2} \mathrm{O}$. Salts of $\mathrm{CsCl}, \mathrm{NaCl}$ and $\mathrm{CaCl}_{2}$ do not form hydrates, which allows In contrast to the hydrate-forming salts $\left(\mathrm{LiBr}, \mathrm{LiCl}, \mathrm{LiNO}_{3}\right)$ the solution to be evaporated (desorbed) to visualization of the process of formation of the smallest salt particles in the solution volume. Salts of $\mathrm{CsCl}, \mathrm{NaCl}$ and $\mathrm{CaCl}_{2}$ do not form hydrates, which allows unlike hydrate forming salts $\left(\mathrm{LiBr}, \mathrm{LiCl}, \mathrm{LiNO}_{3}\right)$, to evaporate (desorb) solutions to visualization of the process of formation of the smallest particles of salt in the solution volume.

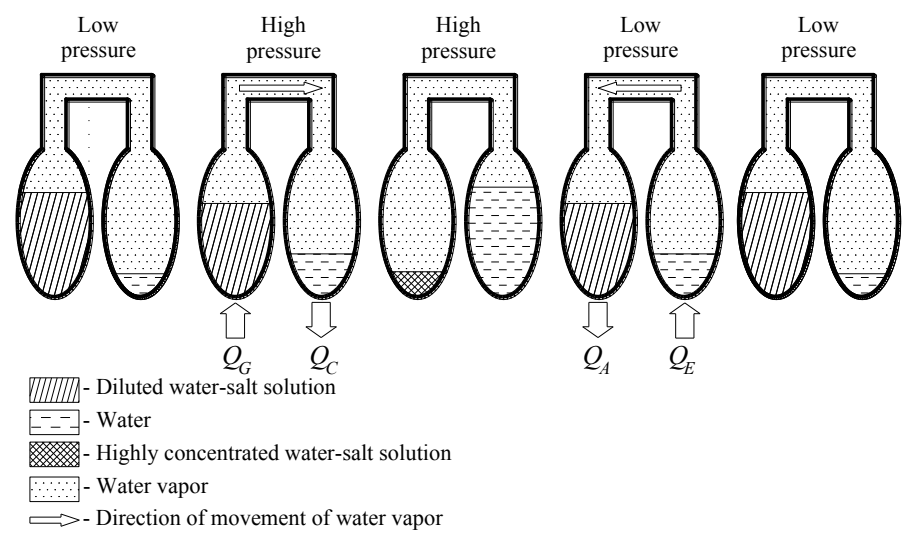

Fig. 2. Operation scheme of ATT of periodic action: $Q_{G}$ - heat input to the generator (desorber); $Q_{C}-$ removal of heat of condensation; $Q_{A}$ - removal of heat of absorption; $Q_{E}$ - heat input to the evaporator.

The laws of spontaneous formation (nucleation) and growth in supersaturated solutions of solid-phase nuclei can be easily studied by examining the desorption of thin films of aqueous-salt solutions on a horizontal heating surface. Depending on the temperature of the heating surface, three basic desorption modes can be realized (Figure 3): evaporation in a layer with a heating surface temperature $\left(T_{S U R}\right)$ is less than the boiling point $\left(T_{B}\right)$ of the solution; bubble boiling, when the surface temperature is equal to or higher than the boiling point, but below the Leidenfrost temperature $\left(T_{L}\right)$; evaporation in a spheroidal state with separation of the solution from the heating surface by a continuous vapor film at a surface temperature above the Leidenfrost temperature [2].

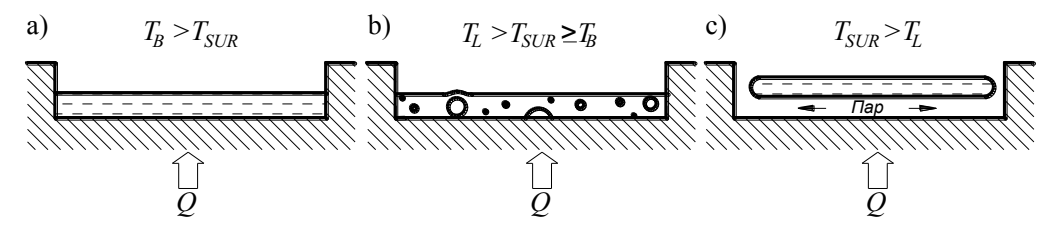

Fig. 3. Basic modes of desorption of water-salt solution: a) evaporation in a layer, b) bubble boiling, c) evaporation in a spheroidal state. 


\section{Results}

The nucleation process in thin films of aqueous-salt solutions was investigated at temperatures of the heating surface lower than the boiling point of the solution (fig. 3a).

In Fig. 4 shows photographs of the process of desorption of a thin film of an aqueous solution of $\mathrm{CsCl}$ on the horizontal heating surface of the experimental setup [3, 4], with a working area made of titanium. The working area was $70 \mathrm{~mm}$ in diameter and the working surface temperature was maintained at $90{ }^{\circ} \mathrm{C}$.
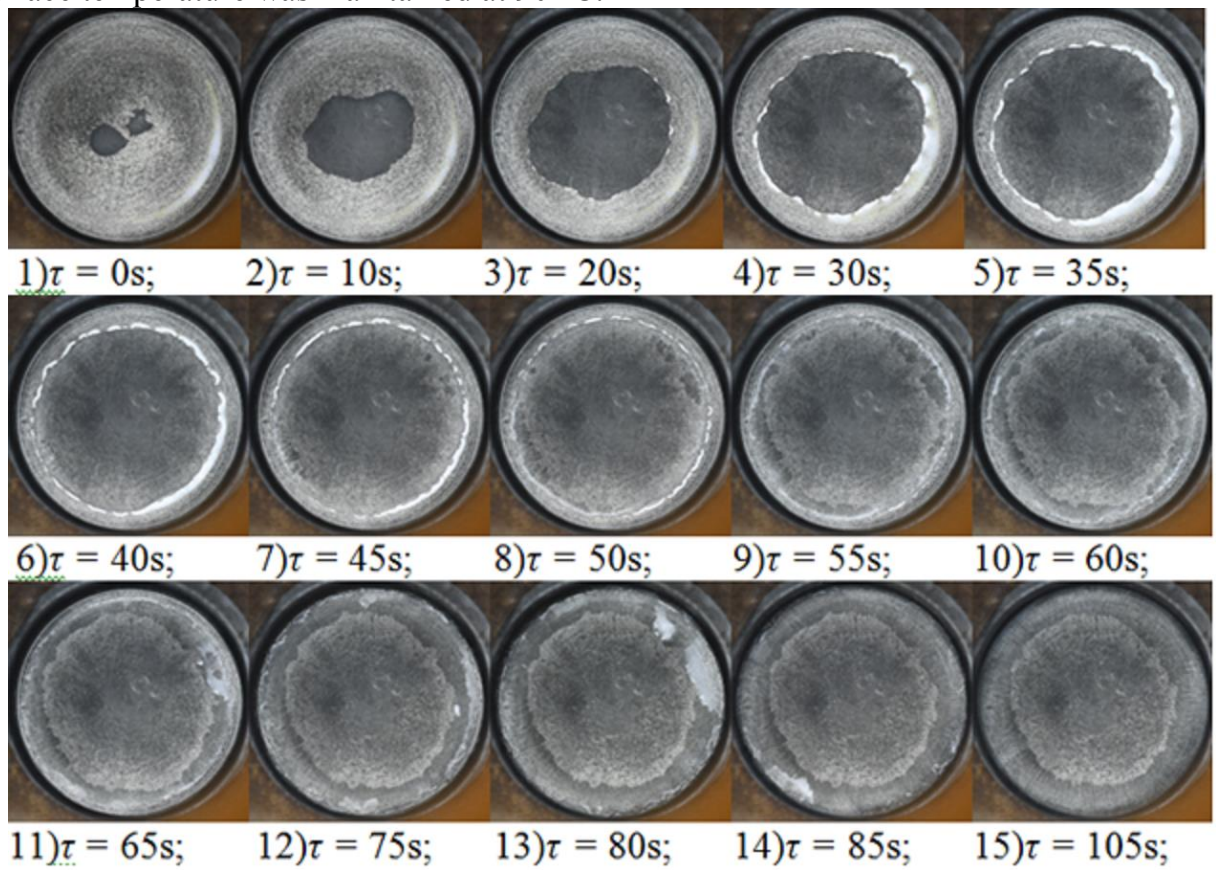

Fig. 4. Development of the process of desorption of water-salt solution $\mathrm{CsCl}$ at $T_{S U R}=90{ }^{\circ} \mathrm{C}$.

When the maximum thickness is reached, determined by the surface tension forces, the thin continuous film of the solution breaks and begins to gradually contract from the center to the periphery of the working area (fig. 4, frames 1-4), forming an zone free of solution. At the same time on the "dry" surface, free from the liquid solution, an uneven trace of the smallest particles of salt is formed. The apparent surface concentration of these particles increases in the direction from the center to the periphery. As the concentration of the solution increases, in places of contact with the heating surface due to a decrease in the thickness of the solution film, the maximum evaporation rate is observed, which leads to the formation of the first nucleation zones (fig. 4, frames 3-4 (light zones at the internal boundary of the solution)). As the concentration increases, a spontaneous process of redistribution of steam across the entire surface of the solution is observed (fig. 4, frames 11-14 (light zones on the surface of the solution)), which is expressed as the appearance of visible areas of salt deposition and their dissolution. Steam moves from the peripheral part of the working area to the inner boundary of the solution film. Relative stabilization of this process for supersaturated solution is achieved through 105s. (fig. 4, frame 15). When the thin vapor-air jet is directed to the surface of the supersaturated solution, a mobile zone of the solution forms in which salt crystals are missing for a while (fig. 5, frames 2-6). 
However, the visible boundary of the crystallization front disappears after 3.5 seconds (fig. 5, frame 7) and the process of dynamic equilibrium again stabilizes in time.

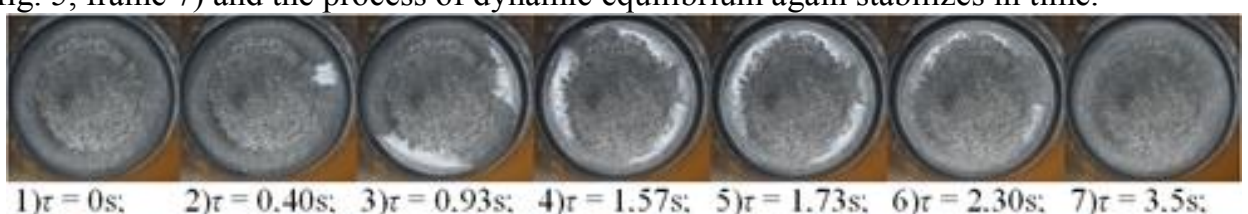

Fig. 5. Dynamics of the motion of the crystallization front in a thin film of a solution.

A similar picture can be observed with the desorption of thin films of aqueous solutions of salts $\mathrm{NaCl}$ and $\mathrm{CaCl}_{2}$. However, the size of single and aggregated crystals formed for these salts is much larger than the size of $\mathrm{CsCl}$ crystals (fig. 6).

a)

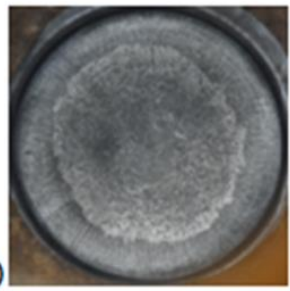

b)

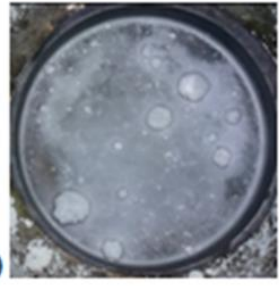

c)

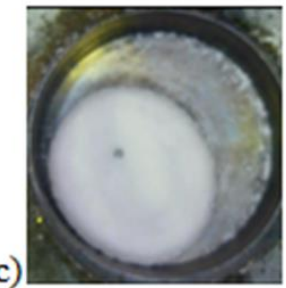

Fig. 6. Crystals of salts on the heating surface $T_{S U R}=90^{\circ} \mathrm{C}$ : a) $\mathrm{CsCl}$; b) $\mathrm{CaCl}_{2}$; c) $\mathrm{NaCl}$.

It is important that, in contrast to supersaturated solutions of salts with a relatively low solubility $\left(\mathrm{NaCl}, \mathrm{CaCl}_{2}\right.$, etc.), supersaturated $\mathrm{CsCl}$ solutions retained the flowability property in the presence of a large number of small unaggregated particles of the solid phase.

\section{Conclusion}

The results of the experiments make it possible to identify a new vector of studies on the intensification of heat and mass transfer processes in devices of absorption thermotransformers: the possibility of operating under the supersaturation of aqueous solutions of highly soluble salts, for example $\mathrm{CsCl}$, which has a higher solubility in water than the widely known LiBr salt.

The work was financially supported by a grant from the Ministry of Science and Education of the Russian Federation, agreement No. 14.Z50.31.0041 of February 13, 2017.

\section{References}

1. A.V. Baranenko, S.V. Karavan, O.A. Pinchuk, D.V. Karavan, Water solutions of absorption thermo-transformers (Pero Publ., Moscow, 2014) [in Russian]

2. S.S. Kutayeladze, Fundamentals of the theory of heat transfer (Atomizdat Publ., Moscow, 1979) [in Russian]

3. V.E. Nakoryakov, S.L. Elistratov, J. Eng. Thermophys., 22, 2 (2009), DOI: 10.1134/S181023281302001X

4. V.E. Nakoryakov, S.L. Elistratov, J. Eng. Thermophys., 18, 3 (2009), DOI: $10.1134 / \mathrm{S} 1810232809030011$ 